\title{
Diet-dependence of metabolic perturbations mediated by the endocrine disruptor tolylfluanid
}

\author{
Shane M Regnier ${ }^{1,2,3}$, Andrew G Kirkley ${ }^{3,4}$, Daniel Ruiz ${ }^{1,3}$, Wakanene Kamau ${ }^{3}$, Qian Wu5, \\ Kurunthachalam Kannan ${ }^{5}$ and Robert M Sargis ${ }^{6}$ \\ ${ }^{1}$ Committee on Molecular Metabolism and Nutrition, Chicago, Illinois, USA \\ ${ }^{2}$ Pritzker School of Medicine, Chicago, Illinois, USA \\ ${ }^{3}$ University of Chicago, Chicago, Illinois, USA \\ ${ }^{4}$ Committee on Molecular Pathogenesis and Molecular Medicine, Chicago, Illinois, USA \\ ${ }^{5}$ Wadsworth Center, New York Department of Health, Albany, New York, USA \\ ${ }^{6}$ Division of Endocrinology, Diabetes, and Metabolism, Department of Medicine, University of Illinois at Chicago, Chicago, Illinois, USA \\ Correspondence should be addressed to R M Sargis: rsargis@uic.edu
}

\begin{abstract}
Emerging evidence implicates environmental endocrine-disrupting chemicals (EDCs) in the pathogenesis of metabolic diseases such as obesity and diabetes; however, the interactions between EDCs and traditional risk factors in disease pathogenesis remain incompletely characterized. The present study interrogates the interaction of the EDC tolylfluanid (TF) and traditional dietary stressors in the promotion of metabolic dysfunction. Eight-week-old male C57BL/6 mice were fed a high-fat, high-sucrose diet (HFHSD) or a high-sucrose diet (HSD), with or without TF supplementation at $100 \mu \mathrm{g} / \mathrm{g}$, for 12 weeks. Food intake, body weight and visceral adiposity were quantified. Glucose homeostasis was interrogated by intraperitoneal glucose and insulin tolerance tests at 9 and 10 weeks of exposure, respectively. After 12 weeks of dietary exposure, metabolic cage analyses were performed to interrogate nutrient handling and energy expenditure. In the background of an HFHSD, TF promoted glucose intolerance; however, weight gain and insulin sensitivity were unchanged, and visceral adiposity was reduced. In the background of an HSD, TF increased visceral adiposity; however, glucose tolerance and insulin sensitivity were unchanged, while weight gain was reduced. Thus, these analyses reveal that the metabolic perturbations induced by dietary exposure to TF, including the directionality of alterations in body weight gain, visceral adiposity and glucose homeostasis, are influenced by dietary macronutrient composition, suggesting that populations may exhibit distinct metabolic risks based on their unique dietary characteristics.
\end{abstract}

\author{
Key Words \\ tolylfluanid \\ - endocrine disruptor \\ $\checkmark$ diet \\ - adiposity \\ - glucose tolerance
}

\section{Introduction}

Global metabolic health has deteriorated dramatically over the last several decades with the emergence of the obesity and diabetes epidemics. Nearly $69 \%$ of the U.S. population is now overweight, with $35 \%$ currently obese (1) and approximately 50\% projected to be obese by 2030 (2). Obesity is a major risk factor for the development of cardiovascular disease, obstructive sleep apnea and nonalcoholic fatty liver disease $(3,4)$, and the societal expansion in fat mass is thought to underlie much of the increasing prevalence of diabetes (5). Worldwide, 415 million individuals are estimated to have diabetes, with this number projected to reach a staggering

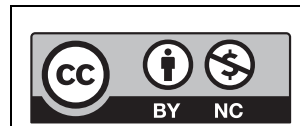

This work is licensed under a Creative Commons Attribution-NonCommercial 4.0 International License. 
642 million by 2040 (6). The pathogeneses of obesity and diabetes are driven primarily by chronic caloric imbalance arising from increased physical inactivity and energy intake. Increasing global consumption of a 'Western' diet consisting of red and processed meats, refined grains, high-fat dairy products and sugary beverages results in a diet enriched in saturated and trans fats as well as simple carbohydrates that promote the development of obesity and diabetes $(7,8)$.

Recently, exposures to endocrine-disrupting chemicals (EDCs) have been implicated as novel metabolic disease risk factors. Indeed, synthetic chemical production correlates with the increasing prevalence of overweight and obesity (9) and diabetes (10). One compound of interest is the fungicide and antifouling agent tolylfluanid (TF). Utilized in agricultural regions outside of the U.S., TF is one of the most commonly detected fungicides in Europe where it has also been identified in groundwater $(11,12,13$, 14). Human exposure likely occurs through ingestion of contaminated food and water as well as occupationally $(15,16)$. However, current human exposure levels have not been tabulated. While not approved for use in the U.S., TF is permitted on imported foodstuffs, including apples, hops, grapes and tomatoes (17).

Previously, we have shown that TF augments adipogenesis in vitro (18) and promotes insulin resistance in rodent and human adipose tissues exposed ex vivo (19). These effects are postulated to result from activation of adipocytic glucocorticoid receptor (GR) signaling $(18,20)$. In recent studies, male C57BL/6 mice exposed to $\mathrm{TF}$ via a standard laboratory chow diet for 12 weeks exhibited increased adiposity, glucose intolerance and insulin resistance with concomitant impairments in adipose insulin sensitivity (21). While this study highlighted a potential role for $\mathrm{TF}$ in metabolic deterioration, the impact of this novel metabolic disruptor in the context of dietary changes which are characteristic of modernity is unknown. To this end, the present study expands upon prior work to elucidate the diet-dependent impact of $\mathrm{TF}$ on energy metabolism.

\section{Methods}

Animal husbandry, tissue processing, diets and EDC exposure

Eight-week-old male C57BL/6 mice were obtained from Jackson Laboratories and housed in pairs at $22.2 \pm 1^{\circ} \mathrm{C}$ under a 12:12-h light-dark cycle (06:00-18:00h light

http://www.endocrineconnections.or https://doi.org/10.1530/EC-17-0320

() 2018 The authors Published by Bioscientifica Ltd cycle). Mice were fed ad libitum with one of the following diets: a high-fat, high-sucrose diet (HFHSD), with fat content primarily derived from milk fat similar to that previously shown to disrupt metabolic homeostasis in mice (22), or a low-fat, high-carbohydrate diet enriched in sucrose (HSD) (Harlan Laboratories, Madison, WI, USA) (Table 1). Animals exposed to TF received an identical diet supplemented with $100 \mu \mathrm{g} / \mathrm{g}$ TF at the time of manufacturing to recapitulate regulatory policy that defines tolerance limits as residue levels per unit weight and to address controversies in TF regulations (23). Animals were weighed biweekly, and food pellets were weighed and replaced weekly. Animals were treated humanely in accordance with protocols approved by the Institutional Animal Care and Use Committee at the University of Chicago. At study termination, animals were euthanized by isoflurane inhalation followed by exsanguination via cardiac puncture followed by adipose depot dissection and quantitation. Adipose samples for histology were fixed in $10 \%$ formalin for $24 \mathrm{~h}$ before paraffin embedding and staining with hematoxylin and eosin.

\section{Intraperitoneal glucose tolerance test (IP-GTT) and serum insulin levels}

After nine weeks of exposure, mice were fasted for $6 \mathrm{~h}$ beginning at 07:30h. Fasting blood glucose levels were measured using a Freestyle Lite glucometer (Abbott Laboratories). Mice then received an IP injection of dextrose ( $2 \mathrm{~g} / \mathrm{kg}$ body weight) with blood glucose concentrations measured serially for $120 \mathrm{~min}$. Fasting blood samples (20-25 $\mu \mathrm{L}$ ) for serum insulin measurement were obtained using heparinized tubes, placed immediately on ice, centrifuged at $1500 \mathrm{~g}$ for $15 \mathrm{~min}$ at $4^{\circ} \mathrm{C}$ and concentrations were determined using a commercial insulin ELISA kit as per the manufacturer's instructions (Millipore).

Table 1 Macronutrient composition of murine diets.

\begin{tabular}{|c|c|c|c|c|}
\hline \multirow{2}{*}{$\begin{array}{l}\text { Diet (code, energy } \\
\text { density) }\end{array}$} & \multicolumn{2}{|c|}{$\begin{array}{c}\text { High-fat, high- } \\
\text { sucrose (HFHSD)* } \\
(\text { TD.120438, } 4.7 \mathrm{kcal} / \mathrm{g})\end{array}$} & \multicolumn{2}{|c|}{$\begin{array}{l}\text { High-sucrose }(\mathrm{HSD}) * * \\
(\mathrm{TD} .140437,3.8 \mathrm{kcal} / \mathrm{g})\end{array}$} \\
\hline & $\%$ by weight & $\begin{array}{l}\% \text { kcal } \\
\text { from }\end{array}$ & $\%$ by weight & $\begin{array}{c}\% \mathrm{kcal} \\
\text { from }\end{array}$ \\
\hline Protein & 17.3 & 14.8 & 14.2 & 14.7 \\
\hline Carbohydrate & 47.6 & 47.6 & 72.5 & 75.5 \\
\hline Fat & 23.2 & 44.6 & 4.2 & 9.7 \\
\hline Saturated & 14.0 & 27.2 & 1.6 & 3.9 \\
\hline Monounsaturated & 7.0 & 13.6 & 1.1 & 2.7 \\
\hline Polyunsaturated & 2.0 & 3.9 & 1.3 & 3.2 \\
\hline \multicolumn{5}{|c|}{$\begin{array}{l}\text { *Sucrose } 340.0 \mathrm{~g} / \mathrm{kg} ; \text { anhydrous milk fat } 210 \mathrm{~g} / \mathrm{kg} ; \text { **sucrose } 703.0 \mathrm{~g} / \mathrm{kg} \text {; } \\
\text { anhydrous milk fat } 20.0 \mathrm{~g} / \mathrm{kg} \text {. }\end{array}$} \\
\hline NC & $\begin{array}{l}\text { This work is lic } \\
\text { Attribution-No } \\
\text { License. }\end{array}$ & $\begin{array}{l}\text { nsed unde } \\
\text { Commerci }\end{array}$ & $\begin{array}{l}\mathrm{r} \text { a Creative Comm } \\
\text { ial } 4.0 \text { Internation }\end{array}$ & \\
\hline
\end{tabular}




\section{Intraperitoneal insulin tolerance test (IP-ITT)}

After 10 weeks of exposure, mice were fasted for $3 \mathrm{~h}$ beginning at 09:00h. Fasting blood glucose levels were measured as above. Mice then received an IP injection of Humalog insulin (0.5 U/kg body weight; Eli Lilly) with blood glucose concentrations measured serially for $90 \mathrm{~min}$.

\section{Metabolic cage analysis}

After 12 weeks on the experimental diets, indirect calorimetric measurements were performed using the LabMaster System (TSE Systems) as previously described (21). The respiratory exchange ratio (RER) was measured as the ratio of $\mathrm{O}_{2}$ inhalation to $\mathrm{CO}_{2}$ production, averaged over a 12-h period. Metabolic flexibility was defined as the absolute change in RER between successive light and dark cycles. Energy expenditure, activity and food consumption were also quantified.

\section{Measurement of dietary TF content}

\section{Chemicals and standards}

Anhydrous sodium sulfate, sodium chloride and acetonitrile were purchased from Mallinckrodt (St Louis, MO, USA). TF (99.6\%) was purchased from Fluka (St Louis, $\mathrm{MO}, \mathrm{USA})$.

\section{Sample preparation}

The extraction of TF followed the QuEChERS method (24), with slight modifications. Briefly, $0.5 \mathrm{~g}$ of diet pellet was transferred into a $15-\mathrm{mL}$ polypropylene tube and homogenized in $10 \mathrm{~mL}$ of acetonitrile by an Ultra-Turrax T25 homogenizer. After the addition of $1 \mathrm{~g}$ of sodium sulfate and $0.25 \mathrm{~g}$ of sodium chloride, the samples were shaken in an orbital shaker for $40 \mathrm{~min}$. The samples were centrifuged at $5000 \boldsymbol{g}$ for $5 \mathrm{~min}$. One milliliter of the supernatant was transferred into an amber autosampler vial for instrumental analysis.

\section{Instrumental analysis}

Instrumental analysis of TF was performed on an Agilent 1100 high-performance liquid chromatography system (Agilent) coupled with an API 2000 tandem mass spectrometer (AB SCIEX, Framingham, MA, USA) (HPLCMS/MS). Five microliters of the sample extract was injected into a BetaSil C18 column $(5 \mu \mathrm{m} ; 150 \mathrm{~mm} \times 2.1 \mathrm{~mm}$; Thermo Scientific). The HPLC mobile phase started with

$\begin{array}{lr}\text { http://www.endocrineconnections.org } & \text { () } 2018 \text { The authors } \\ \text { https://doi.org/10.1530/EC-17-0320 } & \text { Published by Bioscientifica Ltd }\end{array}$

20\% A (100\% acetonitrile) and 80\% B (0.2\% formic acid in water) for $2 \mathrm{~min}$, increased to $95 \% \mathrm{~A}$ at $10 \mathrm{~min}$ followed by a 4-min hold and decreased to $20 \% \mathrm{~A}$ at $15 \mathrm{~min}$ followed by a 5 -min hold reverting to original conditions. The tandem mass spectrometry was operated in the positive ionization mode with the ion spray voltage of $5500 \mathrm{~V}$. The mass transition for TF was 347>137. The dwell time was $400 \mathrm{~ms}$. Collision energy was $32 \mathrm{~V}$ for TF. All other parameters were optimized by infusing the standards in the tune mode.

\section{Quality assurance and quality control}

Procedural blanks were analyzed through the entire analytical procedure with $10 \mathrm{~mL}$ of acetonitrile for every five samples. Duplicate samples were analyzed for every five samples. Matrix spike tests were carried out for each sample type by spiking a known amount of the target compounds at three different concentrations in triplicates. The concentrations in the extracts designed for the matrix spike tests were 200, 1000 and $5000 \mathrm{ng} / \mathrm{mL}$ for TF. The respective mean recovery of TF through the analytical procedure was $85 \%$ for the HFHSD and $88 \%$ for the HSD. Matrix-matched calibration curves for each of the diets were used to calculate the concentrations of TF in samples. The limit of quantification was $1 \mu \mathrm{g} / \mathrm{g}$ for TF.

\section{Statistical analyses}

Adiposity was defined as adipose tissue weight divided by total body weight. Time-dependent variables were assessed by two-way ANOVA with multiple comparisons and Holm-Sidak post hoc test. Glucose and insulin tolerance were measured as the AUC of glucose over time by the trapezoidal method. For all endpoint analyses, individual groups were compared by $F$-testing to determine differences in variance; for $F<0.05, t$-tests were performed with Welch's correction, whereas for $F>0.05$, standard Student's $t$-tests were performed. All analyses were performed using GraphPad Prism version 6.0. A value of $P<0.05$ was considered statistically significant.

\section{Results}

\section{Diet-dependent effects on caloric intake and TF exposure}

Caloric excess drives metabolic dysfunction; however, the macronutrient content of diets may influence the

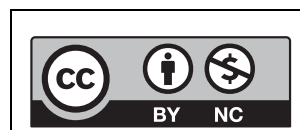

This work is licensed under a Creative Commons Attribution-NonCommercial 4.0 International License. 
ultimate metabolic phenotype, including the impact of EDCs on energy homeostasis. The impact of TF on metabolic outcomes was analyzed within the context of two diets differing in macronutrient composition (Table 1). In neither the HFHSD (Fig. 1A and B) nor the HSD (Fig. 1C and D) did TF alter weekly or total caloric intake. TF was added to the dietary mix at the time of manufacturing at a concentration of $100 \mu \mathrm{g} / \mathrm{g} \quad(0.2879 \mathrm{mmol} / \mathrm{kg})$; final concentrations of TF were measured by HPLC-MS/MS and found to be $64.2 \pm 7.59 \mathrm{mg} / \mathrm{kg}(0.185 \pm 0.022 \mathrm{mmol} / \mathrm{kg})$ in the HFHSD and $62.0 \pm 0.40 \mathrm{mg} / \mathrm{kg} \quad(0.179 \pm 0.001 \mathrm{mmol} / \mathrm{kg})$ in the HSD, which were not significantly different between diets $(P>0.05)$. Based on the quantity of food consumed and the final concentration of TF in each diet, weekly and total TF exposures were not significantly different between HFHSD- and HSD-fed mice (Fig. 1E and F). Taken together, these data suggest that $\mathrm{TF}$ does not modulate total food consumption.

B

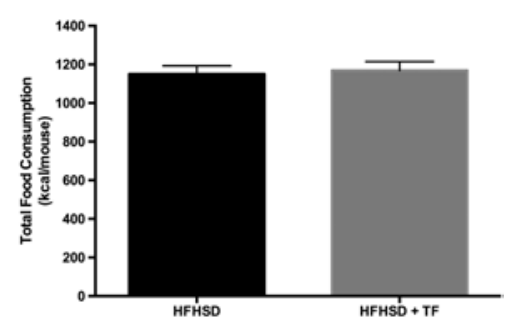

D

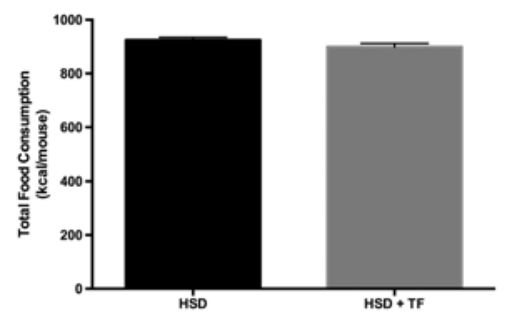

$\mathbf{F}$

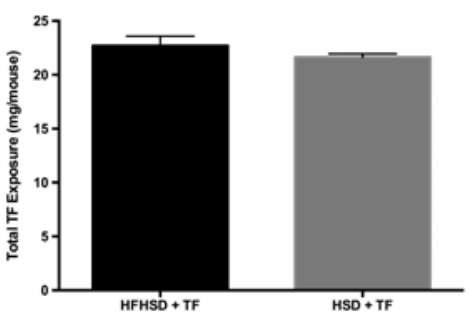

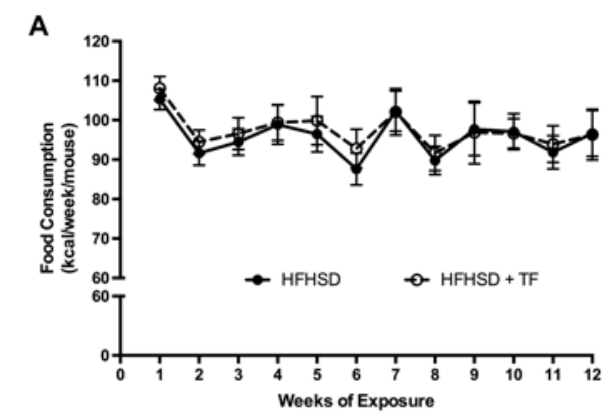
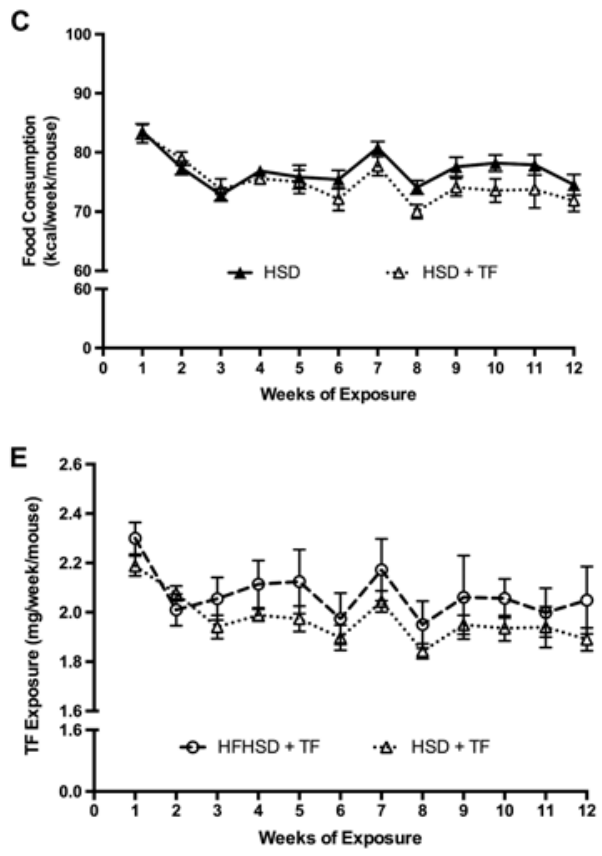

http://www.endocrineconnections.org https://doi.org/10.1530/EC-17-0320
Incorporating TF into an HFHSD impairs glucose tolerance and reduces visceral adiposity

Because consumption of a Western diet is associated with obesity (7), studies were undertaken to interrogate the potential interaction between $\mathrm{TF}$ and macronutrient contents of the diet in promoting metabolic dysfunction. In mice fed an HFHSD, the addition of TF did not modulate weight accrual (Fig. 2A and B). Despite the lack of body weight differences, after 12 weeks of feeding, mice on an HFHSD with TF were found to have a $14.7 \%$ reduction in visceral adiposity relative to the HFHSD controls (Fig. 2C). Histologic analysis of perigonadal/epididymal adipose tissue identified a significant increase in the number of adipocytes per high-power field (hpf) in the TF-treated group (Fig. 2D). Despite this reduction in adiposity, mice fed HFHSD with TF displayed impaired glucose intolerance relative to HFHSD controls (Fig. 2E), with a $20.1 \%$ increase in
C 2018 The authors Published by Bioscientifica Ltd

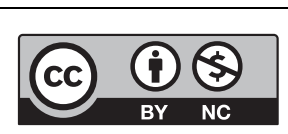

This work is licensed under a Creative Commons Attribution-NonCommercial 4.0 International License.
Figure 1

Caloric intake and TF exposure. Eight-week-old male C57BL/6 mice were provided a high-fat, high-sucrose diet (HFHSD) or high-sucrose diet (HSD) with or without tolylfluanid (TF) added at the time of manufacturing at a concentration of $100 \mu \mathrm{g} / \mathrm{g}$ for 12 weeks. Food consumption was monitored weekly in cages of pair-housed mice. Weekly and total caloric consumption was not altered by TF exposure in the HFHSD (Panels A and $B$ ) or HSD (Panels $C$ and D). TF exposure was calculated using HPLC-MS-measured TF levels, $64.2 \pm 7.59 \mathrm{mg} / \mathrm{kg}(0.185 \pm 0.022 \mathrm{mmol} / \mathrm{kg})$ in the HFHSD and $62.0 \pm 0.40 \mathrm{mg} / \mathrm{kg}(0.179 \pm 0.001 \mathrm{mmol} /$ $\mathrm{kg}$ ) in the HSD, with TF exposure not significantly different between diets (Panels E and F). Data are presented as means \pm S.E.M. $N=11-12$ for each group. 

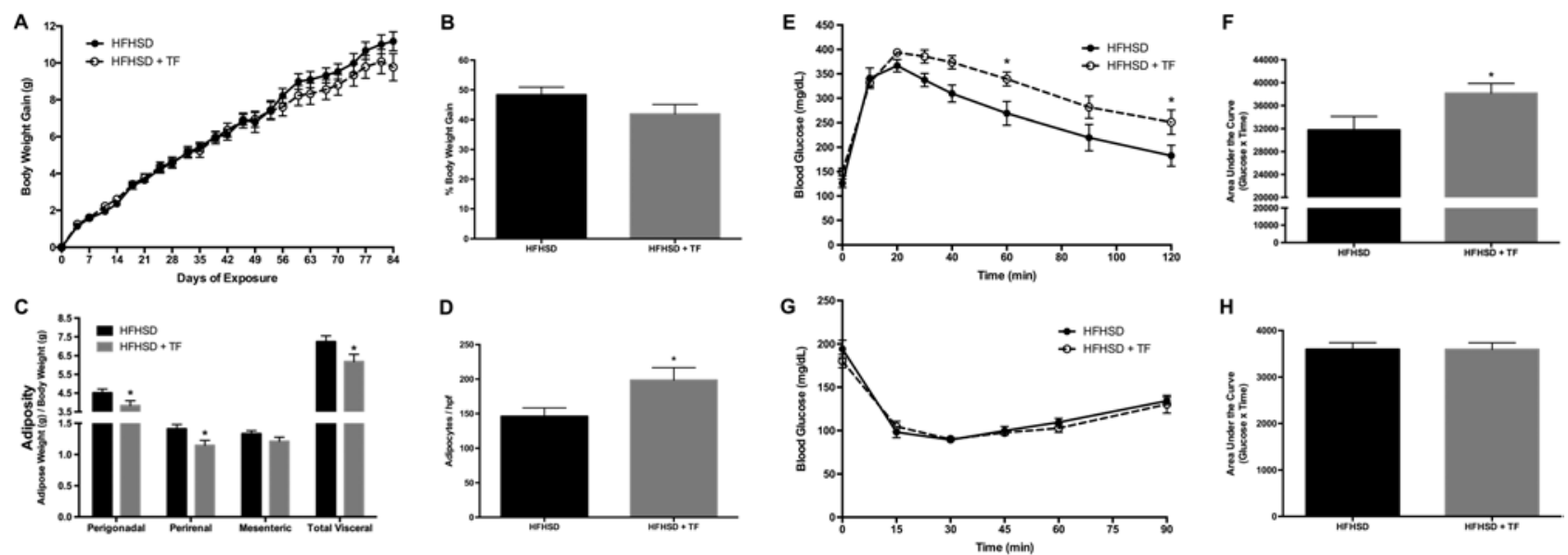

Figure 2

Metabolic impact of TF exposure in the context of a high-fat, high-sucrose diet. Eight-week-old male C57BL/6 mice were provided a high-fat, high-sucrose $\operatorname{diet}$ (HFHSD) with or without tolylfluanid (TF) added at the time of manufacturing at a concentration of $100 \mu \mathrm{g} / \mathrm{g}$ for $12 \mathrm{weeks}$. Body weight was measured twice weekly (Panel A) with fractional body weight gain calculated after 12 weeks (Panel B). At the end of 12 weeks, mice were euthanized and visceral adipose depots (perigonadal/epididymal, perirenal, mesenteric) harvested, weighed and sectioned for histological analysis. Adiposity was calculated as adipose weight normalized to body weight. Exposure to TF led to a reduction in perigonadal, perirenal and total visceral adiposity (Panel C); there was also an increase in the number of adipocytes per high-power field in TF-exposed mice (Panel D). After 9 weeks' exposure, glucose tolerance testing (Panel E) identified relative glucose intolerance in TF-treated mice as measured by the area under the curve (AUC) (Panel F). After 10 weeks' exposure, insulin tolerance testing was performed (Panel G), without significant differences identified between groups (Panel $\mathrm{H}$ ). Data are presented as means \pm S.E.M. $N=25-26$ for body weight and adiposity measures, $6-8$ for glucose tolerance testing and 11 for insulin tolerance testing. ${ }^{*} P<0.05$.

the glucose AUC (Fig. 2F). At this time, fasting insulin levels were not significantly different between groups $(39.35 \pm 3.79 \mu \mathrm{U} / \mathrm{mL}$ for HFHSD vs $40.16 \pm 4.88 \mu \mathrm{U} / \mathrm{mL}$ for HFHSD + TF $(P>0.05))$. Furthermore, despite these differences in glucose tolerance, systemic insulin sensitivity was not altered by $\mathrm{TF}$ exposure in an HFHSD (Fig. 2G and $\mathrm{H}$ ). These findings suggest that consumption of an HFHSD supplemented with TF decreases adiposity and glucose tolerance, without altering body weight gain or insulin sensitivity.

In prior studies using a standard laboratory chow diet, TF altered fuel utilization preference and metabolic flexibility while disrupting diurnal rhythms of energy expenditure and food intake (21). To expand upon these findings, mice were phenotyped in metabolic cages following 12 weeks of exposure to TF in the setting of an HFHSD. In the background of an HFHSD, no significant differences were identified in TF-treated mice when assessing the RER, metabolic flexibility, absolute and corrected energy expenditures, activity or food consumption (Fig. 3A-F). Thus, in the setting of an HFHSD, TF exposure does not alter fuel preference, energy expenditure or metabolic circadian rhythms.
Incorporating TF into an HSD increases adiposity, reduces weight gain and modulates fuel utilization preference and energy expenditure

High dietary sugar consumption is a potent metabolic stressor with the capacity to disrupt insulin-glucose homeostasis and promote obesity development (25). Mice fed an HSD with TF exhibited reduced weight gain relative to HSD controls, ultimately resulting in a $23.3 \%$ decrease in fractional weight gain after 12 weeks (Fig. 4A and B). Interestingly, although the addition of TF to an HSD led to reduced weight gain, the same mice were found to have a $12.3 \%$ increase in visceral adiposity, with specific increases in perigonadal/epididymal, perirenal and mesenteric adipose depots (Fig. 4C). No significant difference in the number of adipocytes per hpf was identified with TF exposure (Fig. 4D). When the same mice were metabolically challenged via IP-GTT and IP-ITT, no differences in glucose tolerance (Fig. 4E and F) or insulin sensitivity (Fig. $4 \mathrm{G}$ and $\mathrm{H}$ ) were identified. In addition, fasting insulin levels at the time of IP-GTT were not significantly different $(8.21 \pm 0.64 \mu \mathrm{U} / \mathrm{mL}$ for HSD vs $10.09 \pm 1.27 \mu \mathrm{U} / \mathrm{mL}$ for $\mathrm{HSD}+\mathrm{TF}(P>0.05))$. Thus, consumption of an HSD supplemented with TF promotes http://www.endocrineconnections.org https://doi.org/10.1530/EC-17-0320
() 2018 The authors Published by Bioscientifica Ltd

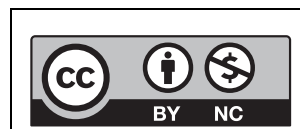

This work is licensed under a Creative Commons Attribution-NonCommercial 4.0 International License. 


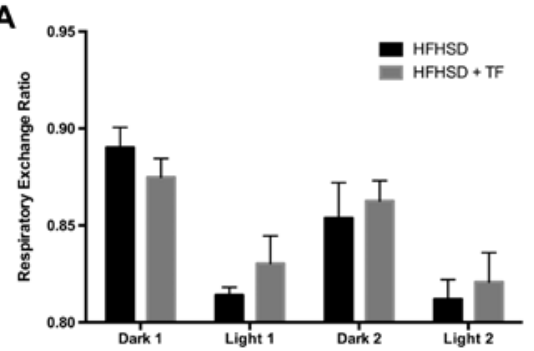

C

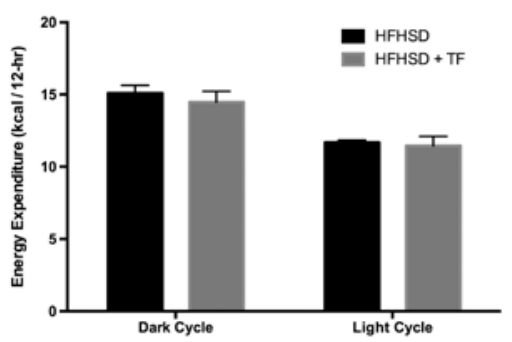

E

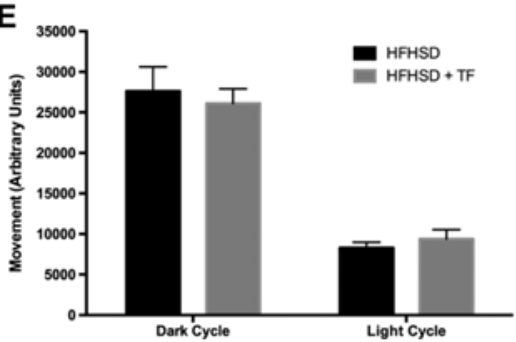

B

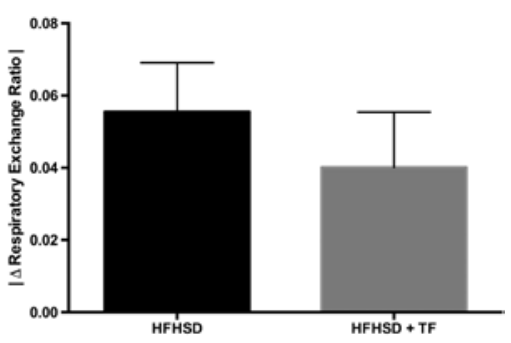

D
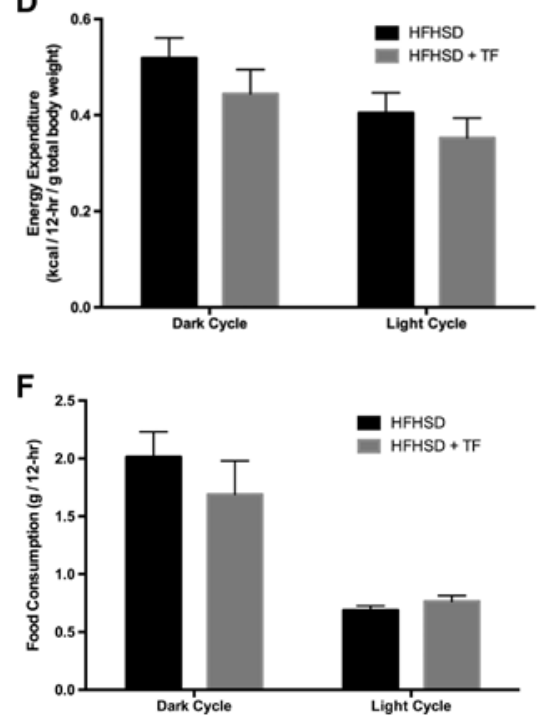

Figure 3

Metabolic cage analyses on a high-fat, highsucrose diet. Eight-week-old male C57BL/6 mice were provided a high-fat, high-sucrose diet (HFHSD) with or without tolylfluanid (TF) added at the time of manufacturing at a concentration of $100 \mu \mathrm{g} / \mathrm{g}$ for 12 weeks. After 12 weeks' exposure, mice were singly housed in metabolic cages and continued on their respective diets. The respiratory exchange ratio (RER) was calculated by the ratio of $\mathrm{O}_{2}$ inhalation to $\mathrm{CO}_{2}$ production, with higher values suggesting an increased preference for carbohydrate as fuel relative to lipid. There were no differences in circadian fuel preference (Panel A) or in metabolic flexibility (Panel B). There were no differences in absolute or body mass-adjusted energy expenditure (Panels $C$ and $D$, respectively). There were no differences in activity (Panel E) or food consumption (Panel F). Data are presented as means \pm S.E.M. $N=4$ per group.

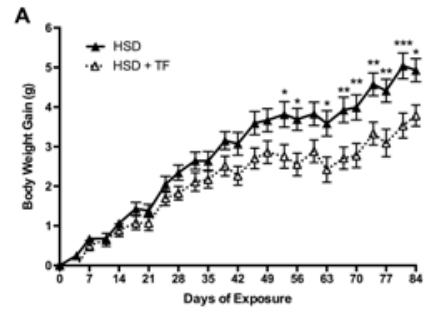

B
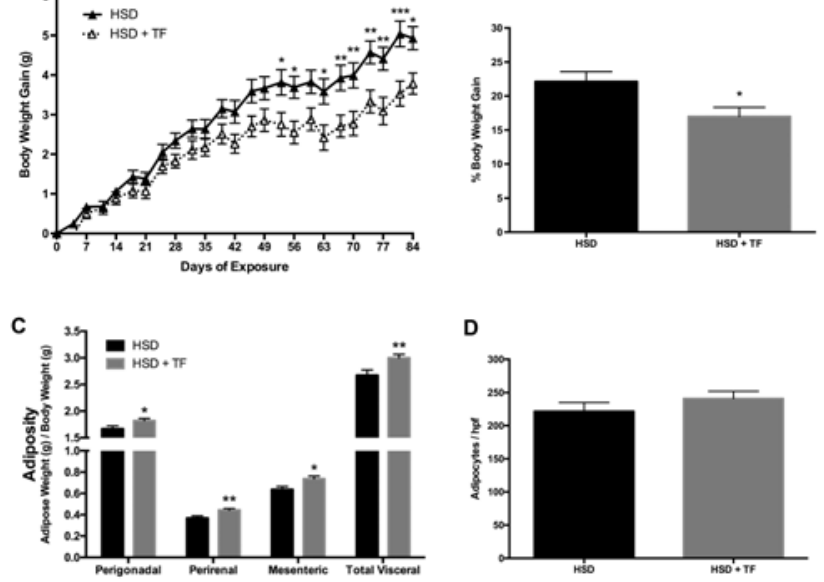

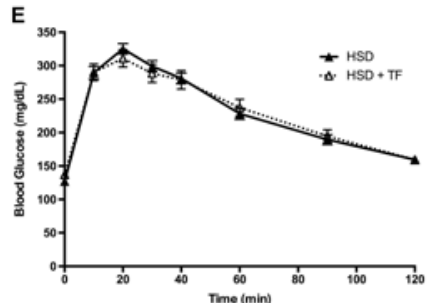

$\mathbf{F}$
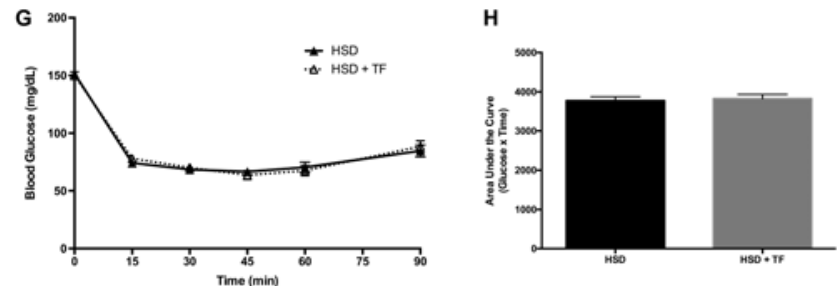

Figure 4

Metabolic impact of TF exposure in the context of a high-sucrose diet. Eight-week-old male C57BL/6 mice were provided a high-sucrose diet (HSD) with or without tolylfluanid (TF) added at the time of manufacturing at a concentration of $100 \mu \mathrm{g} / \mathrm{g}$ for 12 weeks. Body weight was measured twice weekly (Panel A) with fractional body weight gain calculated after 12 weeks, with a significant reduction in weight gain in the TF-exposed group (Panel B). At the end of 12 weeks, mice were euthanized and visceral adipose depots (perigonadal/epididymal, perirenal, mesenteric) harvested, weighed and sectioned for histological analysis. Adiposity was calculated as adipose weight normalized to body weight. Exposure to TF led to an increase in adiposity for all visceral depots (Panel C), without a difference in the number of adipocytes per high-power field (Panel D). After 9 weeks' exposure, glucose tolerance testing (Panel E) did not reveal significant differences between groups (Panel F). After 10 weeks' exposure, insulin tolerance testing was performed (Panel G), without significant differences identified between groups (Panel H). Data are presented as means \pm s.E.M. $N=23-24$ for body weight and adiposity measures, and $20-21$ for glucose and insulin tolerance testing. ${ }^{*} P<0.05 ; * * P<0.01 ; * * * P<0.001$.

$\begin{array}{lr}\text { http://www.endocrineconnections.org } & \text { ○ } 2018 \text { The authors } \\ \text { https://doi.org/10.1530/EC-17-0320 } & \text { Published by Bioscientifica Ltd }\end{array}$

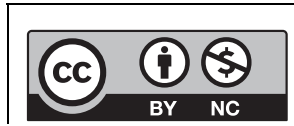

This work is licensed under a Creative Commons Attribution-NonCommercial 4.0 International License. 
A

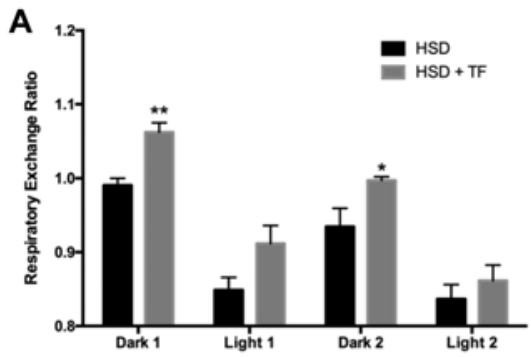

C

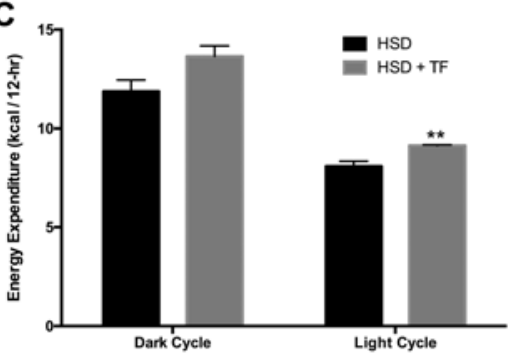

E

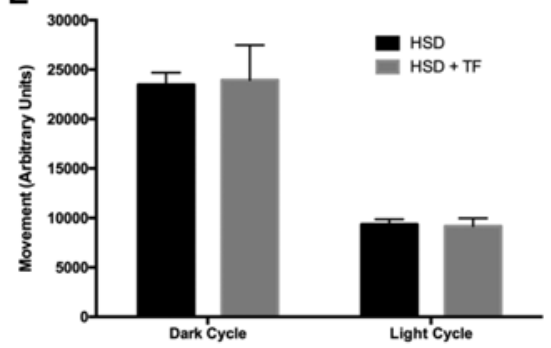

B

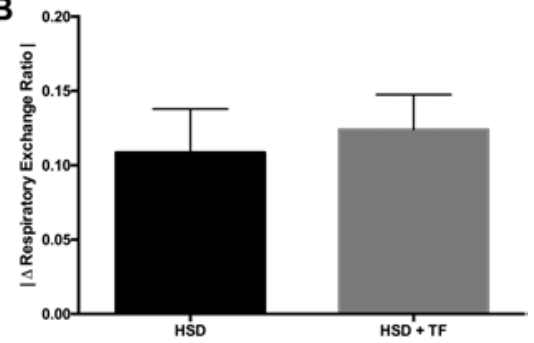

D

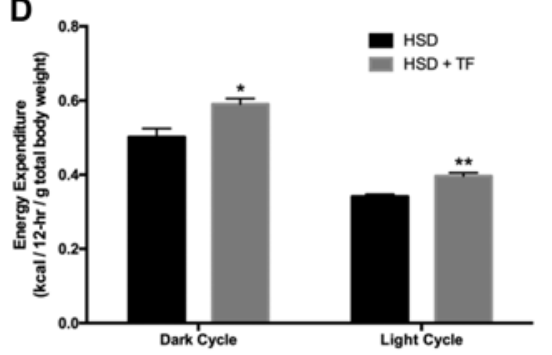

$\mathbf{F}$

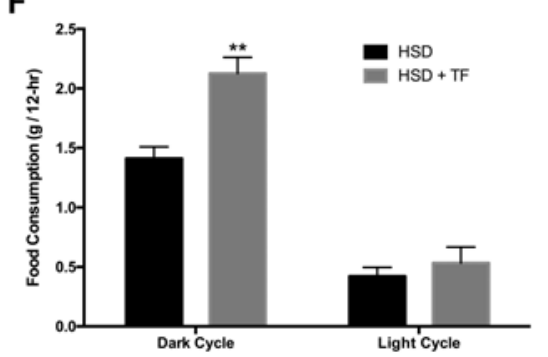

Figure 5

Metabolic cage analyses on a high-sucrose diet. Eight-week-old male C57BL/6 mice were provided a high-sucrose diet (HSD) with or without tolylfluanid (TF) added at the time of manufacturing at a concentration of $100 \mu \mathrm{g} / \mathrm{g}$ for 12 weeks. After 12 weeks' exposure, mice were singly housed in metabolic cages and continued on their respective diets. The respiratory exchange ratio (RER) was calculated by the ratio of $\mathrm{O}_{2}$ inhalation to $\mathrm{CO}_{2}$ production, with higher values suggesting an increased preference for carbohydrate as fuel relative to lipid. Mice exposed to TF exhibited a fuel utilization preference for carbohydrate during dark cycles (Panel A), without differences in metabolic flexibility (Panel B). In the TF-exposed group, absolute energy expenditure was increased during the light cycle (Panel C), and when correcting for total body mass, energy expenditure was increased during both dark and light cycles in TF-exposed mice (Panel D). There were no differences in activity between groups (Panel E). Food consumption during the dark cycle was increased in the TF-exposed group (Panel F). Data are presented as means \pm S.E.M. $N=4$ per group. ${ }^{*} P<0.05 ; * * P<0.01$. increased visceral adiposity with a concurrent reduction in weight gain; however, despite this increase in adiposity, insulin-glucose homeostasis was preserved.

When HSD-fed mice were analyzed in metabolic cages, exposure to TF increased RER during dark cycles, suggesting enhanced utilization of carbohydrate relative to fat as an energy source (Fig. 5A). This change occurred without impacting metabolic flexibility, likely because RER was also non-significantly higher during the light cycle as well (Fig. 5B). Exposure to TF also led to a significant increase in absolute energy expenditure during the light cycle (Fig. 5C). When corrected for total body weight, TF treatment increased energy expenditure during both light and dark cycles (Fig. 5D). TF supplementation of the HSD did not affect activity (Fig. 5E). While overall food intake was not affected by TF exposure over the duration of the study (Fig. 1C and D), TF-exposed mice on an HSD exhibited higher food consumption during the dark cycle (Fig. 5F). Of note, daily food intake in the HSD group, but not the TF-exposed group on HSD, was significantly reduced during the metabolic cage analysis relative to the calculated daily food consumption during the other

http://www.endocrineconnections.org https://doi.org/10.1530/EC-17-0320

C) 2018 The authors Published by Bioscientifica Ltd studies discussed herein (data not shown; $P<0.05$ ). Taken together, these findings suggest that in the setting of an HSD, TF exposure modulates fuel utilization, energy expenditure and food consumption.

\section{Discussion}

Human metabolic health has deteriorated dramatically in recent decades, concurrent with alterations in diet composition and increasing exposure to environmental pollutants. We have postulated that the interactions among various metabolic stressors underlie an individual's disintegration of metabolic integrity (26). Previously, the phenylsulfamide fungicide and booster biocide TF, when consumed in the background of a standard laboratory chow diet (Teklad 2018), promoted increased body weight gain, visceral adiposity, glucose intolerance and insulin resistance (21). In the present study, the interaction between dietary stressors and EDC exposure in promoting metabolic dysfunction was examined utilizing the same EDC, animal model and route of exposure. When coupled

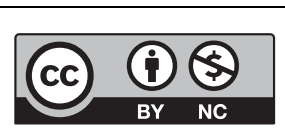

This work is licensed under a Creative Commons Attribution-NonCommercial 4.0 International License. 
with an HFHSD, TF promoted glucose intolerance; however, adiposity was reduced, while weight gain and insulin sensitivity remained unchanged (Fig. 2). In contrast, addition of TF to an HSD led to increased adiposity; however, weight gain was reduced, while glucose tolerance and insulin sensitivity were unaffected (Fig. 4). Importantly, weekly and total TF exposures were equivalent between the HFHSD and the HSD (Fig. 1). Thus, these findings suggest that the macronutrient composition of the diet through which TF exposure occurs alters TF-dependent metabolic outcomes.

While EDCs have emerged as contributors to metabolic disease pathogenesis, it is well recognized that calorically dense diets are potent contributors to the observed increase in obesity and related metabolic diseases. In animal models, mice fed a high-fat diet are known to develop obesity, insulin resistance and glucose intolerance (27). In addition to high levels of saturated and trans fats, Western diets are characterized by high quantities of sugar, particularly sucrose and high fructose corn syrup, principally from added sweeteners (28). Importantly, consumption of sucrose as a caloric sweetener in the U.S. increased 43\% between 1950 and 2000, with per capita consumption now over 65 pounds annually (28). Interestingly, when fed a sucrose-supplemented diet, pregnant mice developed increased adiposity and dyslipidemia (29). In another study, when given a diet high in both sucrose and fat, male mice developed obesity and metabolic dysfunction in only 4 weeks (22). While the impact of high-fat diets on the metabolic effects of EDCs has begun to be investigated $(30,31)$, the impact of high sugar diets has not received much attention. Based on the data presented herein, further work in this area is needed as EDC effects on metabolic outcomes may be nutrient-dependent.

Metabolic cage analyses allow for precise examination of movement, nutrient consumption and energy expenditure. In prior studies, consumption of a standard chow diet with TF for 12 weeks promoted a state of relative metabolic inflexibility and an increased reliance on lipids as an energy source during the dark cycle (21). This metabolic disruption is directionally similar to that observed in mice fed a high-fat diet (32), and in obese humans (33). In the present study, mice fed an HSD supplemented with TF exhibited enhanced carbohydrate utilization during the dark cycle relative to HSD controls (Fig. 5A). Of note, in the HSD group, daily food consumption was significantly reduced during the metabolic cage analysis in which mice were singly housed, relative to the calculated daily food

$$
\text { http://www.endocrineconnections.org }
$$

consumption under standard pair-housing for the other studies discussed herein; this finding was not observed for the group fed TF-enriched HSD nor either HFHSD group. This finding may be secondary to the effects of cumulative exposure to TF over 12 weeks in the setting of an HSD or to diet-specific TF-mediated changes in response to social isolation. This reduced caloric intake by HSD-fed controls may partially explain the relative increase in food consumption of TF-treated mice consuming an HSD during the metabolic cage analyses (Fig. 5F), since TF did not alter caloric intake over the duration of the 12-week exposure study (Fig. 1C and D). Furthermore, the increase in carbohydrate-rich food consumption by TF-treated HSD mice may contribute to the observed carbohydrate utilization preference (Fig. 5A). Alternatively, this enhanced carbohydrate utilization with TF may reflect TF-mediated shifts in nutrient handling, as a prior study showed that TF reduced expression of fatty acid oxidation genes (21). Interestingly, the increased energy expenditure observed in TF-treated HSD-fed mice (Fig. 5C and D) may contribute to the reduction in weight gain identified through 12 weeks of TF exposure (Fig. $4 \mathrm{~A}$ and B).

The findings presented herein provide insights into the interplay between environmental contaminants and diet composition, which may have important effects on metabolic health disparities. Black and Hispanic adults and children have increased rates of overweight and obesity relative to Caucasians $(1,34)$. While many factors contribute to this, minorities and the socioeconomically disadvantaged are more likely to reside in food deserts, regions defined by limited access to fresh foods, forcing increased reliance on prepackaged and fast foods high in the same macronutrients utilized in the present study (35). Unsurprisingly, individuals in the same demographic groups have a higher prevalence of obesity, diabetes and cardiovascular disease (36). In addition to these dietary stressors, low-income and minority communities also suffer a greater burden of pollutant exposure (37). For example, urinary concentrations of the common EDC bisphenol A are inversely correlated with income (38), while demographic analyses demonstrated a disproportionately higher percentage of minority individuals living nearest to high-risk chemical exposure areas (39). Consequently, understanding the interplay between diet and EDC exposure will be vital for addressing the contribution of disproportionate environmental exposures to obesity and diabetes disparities (37).

While the present findings suggest that TF differentially modulates energy handling based upon dietary context,

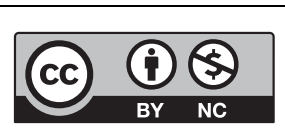

This work is licensed under a Creative Commons Attribution-NonCommercial 4.0 International License. 
this study has several limitations. Although postprocessing concentrations of TF were equivalent between the HFHSD and the HSD, tissue concentrations were not assessed, precluding direct comparison of TF-dependent effects between diets. Because TF is lipophilic (log octanolto-water partition coefficient $\left(K_{\mathrm{ow}}\right)$ of $\left.3.9(17)\right)$, differential gastrointestinal absorption related to dietary fat content is a possibility, as shown for diethylhexyl phthalate (40). Furthermore, although consumption of TF was equivalent across diets, caloric intake was not (Fig. 1), thus precluding direct comparison between diets. Despite these limitations, the observed differences in the directionality of TF effects on metabolic outcome measures suggest that diet macronutrient content modulates TF-mediated alterations on weight gain, adiposity and glucose tolerance. These findings provide justification for future investigations using a pair-feeding model matching both exposure and caloric intake while ensuring comparable internal TF levels. In addition, future studies may expand the scope of dietary content to include other common components of the Western diet, such as fructose and other animal fats. Finally, future studies hope to decipher the molecular mechanisms by which TF interacts with dietary macronutrients to alter energy homeostasis. Given the importance of GR signaling in regulating energy metabolism and the capacity of TF to modulate signaling through this pathway $(18,20,41,42)$, efforts to understand the impact of TF on GR signaling in the context of dietary manipulation will be particularly important for linking disparate metabolic phenotypes to underlying molecular mechanisms. This is particularly important in the context of studies suggesting that the impact of TF on metabolic physiology may not be universal (43).

The present study extends prior findings demonstrating TF-induced metabolic disruption by identifying novel interactions between $\mathrm{TF}$ and diet macronutrient content in the disruption of key metabolic parameters, including weight gain, adiposity and glucose tolerance. Evidence that diet composition modulates the metabolic consequences of pesticide residues suggests that Environmental Protection Agency tolerance limits may need modification based on the dietary vehicle through which exposure occurs. Moreover, these findings highlight the important role of diet in mediating outcomes of EDC exposure, a crucial consideration for understanding the complexity of factors responsible for the pathogenesis of obesity and diabetes.

\section{Declaration of interest}

The authors declare that they have no conflicts pertinent to this manuscript.

\section{Funding}

Work supported by the National Institutes of Health: K08-ES019176 and R21-ES021354 to R M S, T32-HD007009 to S M R and D R, a Pilot and Feasibility Grant from the NIH-funded University of Chicago Diabetes Research and Training Center (P60-DK020595 to R M S) and the ChicAgo Center for Health and EnvironmenT (CACHET, P30-ES027792 to R M S). This work was also supported by the American Diabetes Association (1-17-JDF033 to $\mathrm{R} M \mathrm{~S}$ ).

\section{Acknowledgements}

The authors would like to thank Nicole Massad for her contributions.

\section{References}

1 Ogden CL, Carroll MD, Kit BK \& Flegal KM. Prevalence of childhood and adult obesity in the United States, 2011-2012. JAMA 2014311 806-814. (https://doi.org/10.1001/jama.2014.732)

2 Wang YC, McPherson K, Marsh T, Gortmaker SL \& Brown M. Health and economic burden of the projected obesity trends in the USA and the UK. Lancet 2011378 815-825. (https://doi.org/10.1016/S01406736(11)60814-3)

3 Romero-Corral A, Caples SM, Lopez-Jimenez F \& Somers VK. Interactions between obesity and obstructive sleep apnea: implications for treatment. Chest 2010137 711-719. (https://doi. org/10.1378/chest.09-0360)

4 Jung UJ \& Choi MS. Obesity and its metabolic complications: the role of adipokines and the relationship between obesity, inflammation, insulin resistance, dyslipidemia and nonalcoholic fatty liver disease. International Journal of Molecular Sciences 201415 6184-6223. (https://doi.org/10.3390/ijms15046184)

5 Chan JM, Rimm EB, Colditz GA, Stampfer MJ \& Willett WC. Obesity, fat distribution, and weight gain as risk factors for clinical diabetes in men. Diabetes Care 199417 961-969. (https://doi.org/10.2337/ diacare.17.9.961)

6 International Diabetes Federation. IDF Diabetes Atlas, 7th edition. Brussels, Belgium: International Diabetes Federation, 2016. (available at: http://www.idf.org/diabetesatlas)

7 Fung TT, Rimm EB, Spiegelman D, Rifai N, Tofler GH, Willett WC \& $\mathrm{Hu}$ FB. Association between dietary patterns and plasma biomarkers of obesity and cardiovascular disease risk. American Journal of Clinical Nutrition 200173 61-67.

8 Montonen J, Knekt P, Harkanen T, Jarvinen R, Heliovaara M, Aromaa A \& Reunanen A. Dietary patterns and the incidence of type 2 diabetes. American Journal of Epidemiology $2005161219-227$. (https://doi.org/10.1093/aje/kwi039)

9 Baillie-Hamilton PF. Chemical toxins: a hypothesis to explain the global obesity epidemic. Journal of Alternative and Complementary Medicine 20028 185-192. (https://doi.org/10.1089/107555302317371479)

10 Neel BA \& Sargis RM. The paradox of progress: environmental disruption of metabolism and the diabetes epidemic. Diabetes 2011 60 1838-1848. (https://doi.org/10.2337/db11-0153)

11 Stensvand A \& Christiansen A. Investigation on fungicide residues in greenhouse-grown strawberries. Journal of Agricultural and Food Chemistry 200048 917-920. (https://doi.org/10.1021/jf990418k)

12 Stepan R, Ticha J, Hajslova J, Kovalczuk T \& Kocourek V. Baby food production chain: pesticide residues in fresh apples and products. Food Additives and Contaminants 200522 1231-1242. (https://doi. org/10.1080/02652030500239623)

13 Sadlo S, Szpyrka E, Jazwa A \& Zawislak A. Pesticide residues in fruit and vegetables from Southeastern Poland, 2004-05. Polish Journal of Environmental Studies 200716 313-319.

14 Reemtsma T, Alder L \& Banasiak U. Emerging pesticide metabolites in groundwater and surface water as determined by the application of

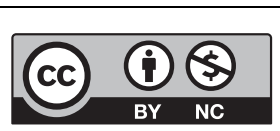

This work is licensed under a Creative Commons Attribution-NonCommercial 4.0 International License. 
a multimethod for 150 pesticide metabolites. Water Research 201347 5535-5545. (https://doi.org/10.1016/j.watres.2013.06.031)

15 Tielemans E, Louwerse E, de Cock J, Brouwer D, Zielhuis G \& Heederik D. Exposure to fungicides in fruit growing: re-entry time as a predictor for dermal exposure. American Industrial Hygiene Association Journal 199960 789-793. (https://doi.org/10.1080/00028899908984503)

16 Links I, Van Der Jagt KE, Christopher Y, Lurvink M, Schinkel J, Tielemans E \& Van Hemmen JJ. Occupational exposure during application and removal of antifouling paints. Annals of Occupational Hygiene 200751 207-218. (https://doi.org/10.1093/annhyg/mel074)

17 Environmental Protection Agency. Pesticide Fact Sheet: Tolylfluanid. Washington DC, USA: US EPA, 2002. (available at: https://www3. epa.gov/pesticides/chem_search/reg_actions/registration/fs_ PC-309200_01-Sep-02.pdf)

18 Sargis RM, Johnson DN, Choudhury RA \& Brady MJ. Environmental endocrine disruptors promote adipogenesis in the 3T3-L1 cell line through glucocorticoid receptor activation. Obesity 201018 1283-1288. (https://doi.org/10.1038/oby.2009.419)

19 Sargis RM, Neel BA, Brock CO, Lin Y, Hickey AT, Carlton DA \& Brady MJ. The novel endocrine disruptor tolylfluanid impairs insulin signaling in primary rodent and human adipocytes through a reduction in insulin receptor substrate-1 levels. Biochimica et Biophysica Acta 2012 1822 952-960. (https://doi.org/10.1016/j.bbadis.2012.02.015)

20 Neel BA, Brady MJ \& Sargis RM. The endocrine disrupting chemical tolylfluanid alters adipocyte metabolism via glucocorticoid receptor activation. Molecular Endocrinology 201327 394-406. (https://doi. org/10.1210/me.2012-1270)

21 Regnier SM, Kirkley AG, Ye H, El-Hashani E, Zhang X, Neel BA, Kamau W, Thomas CC, Williams AK, Hayes ET, et al. Dietary exposure to the endocrine disruptor tolylfluanid promotes global metabolic dysfunction in male mice. Endocrinology 2015156 896-910. (https://doi.org/10.1210/en.2014-1668)

22 Yang ZH, Miyahara H, Takeo J \& Katayama M. Diet high in fat and sucrose induces rapid onset of obesity-related metabolic syndrome partly through rapid response of genes involved in lipogenesis, insulin signalling and inflammation in mice. Diabetology and Metabolic Syndrome 20124 32. (https://doi.org/10.1186/1758-5996-4-32)

23 European Food Safety Authority. Reasoned opinion on the review of the existing maximum residue levels (MRLs) for tolylfluanid according to Article 12 of Regulation (EC) No 396/2005. European Food Safety Authority Journal 201311 3300. (https://doi.org/10.2903/j. efsa.2013.3300)

24 Lehotay SJ, de Kok A, Hiemstra M \& Van Bodegraven P. Validation of a fast and easy method for the determination of residues from 229 pesticides in fruits and vegetables using gas and liquid chromatography and mass spectrometric detection. Journal of $A O A C$ International 200588 595-614.

25 DiNicolantonio JJ \& Berger A. Added sugars drive nutrient and energy deficit in obesity: a new paradigm. Open Heart 20163 e000469. (https://doi.org/10.1136/openhrt-2016-000469)

26 Sargis RM. Metabolic disruption in context: clinical avenues for synergistic perturbations in energy homeostasis by endocrine disrupting chemicals. Endocrine Disruptors 20153 e1080788. (https://doi.org/10.1080/23273747.2015.1080788)

27 Winzell MS \& Ahren B. The high-fat diet-fed mouse: a model for studying mechanisms and treatment of impaired glucose tolerance and type 2 diabetes. Diabetes 200453 (Supplement 3) S215-S219. (https://doi.org/10.2337/diabetes.53.suppl_3.S215)

28 U.S. Department of Agriculture. Agriculture Fact Book 2001-2002. Washington DC, USA: United States Department of Agriculture, 2003. (available at: http://www.usda.gov/factbook/2002factbook.pdf)
29 Toop CR, Muhlhausler BS, O'Dea K \& Gentili S. Consumption of sucrose, but not high fructose corn syrup, leads to increased adiposity and dyslipidaemia in the pregnant and lactating rat. Journal of Developmental Origins of Health and Disease 20156 38-46. (https://doi.org/10.1017/S2040174414000610)

30 Lim S, Ahn SY, Song IC, Chung MH, Jang HC, Park KS, Lee KU, Pak YK \& Lee HK. Chronic exposure to the herbicide, atrazine, causes mitochondrial dysfunction and insulin resistance. PLOS ONE 20094 e5186. (https://doi.org/10.1371/journal.pone.0005186)

31 Ding S, Fan Y, Zhao N, Yang H, Ye X, He D, Jin X, Liu J, Tian C, Li H, et al. High-fat diet aggravates glucose homeostasis disorder caused by chronic exposure to bisphenol A. Journal of Endocrinology 2014221 167-179. (https://doi.org/10.1530/JOE-13-0386)

32 Koves TR, Ussher JR, Noland RC, Slentz D, Mosedale M, Ilkayeva O, Bain J, Stevens R, Dyck JR, Newgard CB, et al. Mitochondrial overload and incomplete fatty acid oxidation contribute to skeletal muscle insulin resistance. Cell Metabolism 20087 45-56. (https://doi. org/10.1016/j.cmet.2007.10.013)

33 van Herpen NA, Schrauwen-Hinderling VB, Schaart G, Mensink RP \& Schrauwen P. Three weeks on a high-fat diet increases intrahepatic lipid accumulation and decreases metabolic flexibility in healthy overweight men. Journal of Clinical Endocrinology and Metabolism 2011 96 E691-E695. (https://doi.org/10.1210/jc.2010-2243)

34 Flegal KM, Carroll MD, Kit BK \& Ogden CL. Prevalence of obesity and trends in the distribution of body mass index among US adults, 1999-2010. JAMA 2012307 491-497. (https://doi.org/10.1001/ jama.2012.39)

35 Wrigley N, Warm D \& Margetts B. Deprivation, diet, and food-retail access: findings from the Leeds 'Food Deserts' study. Environment and Planning A 200335 151-188. (https://doi.org/10.1068/a35150)

36 Mari Gallagher Research \& Consulting Group. The Chicago Food Desert Progress Report., Chicago, IL, USA: Mari Gallagher Research \& Consulting Group, 2011. (available at: http://www.marigallagher.com/projects/)

37 Ruiz D, Becerra M, Jagai JS, Ard K \& Sargis RM. Disparities in environmental exposures to endocrine-disrupting chemicals and diabetes risk in vulnerable populations. Diabetes Care $2018 \mathbf{4 1}$ 193-205. (https://doi.org/10.2337/dc16-2765)

38 Nelson JW, Scammell MK, Hatch EE \& Webster TF. Social disparities in exposures to bisphenol A and polyfluoroalkyl chemicals: a crosssectional study within NHANES 2003-2006. Environmental Health 201211 10. (https://doi.org/10.1186/1476-069X-11-10)

39 Orum P, Moore M, Roberts M \& Sanchez J. Who's in Danger? Race, Poverty, and Chemical Disasters. Environmental Justice and Health Alliance for Chemical Policy Reform, 2014. (available at: http:// comingcleaninc.org/assets/media/images/Reports/Who's\%20in\%20 Danger\%20Report\%20FINAL.pdf)

40 Stein MS, Caasi PI \& Nair PP. Influence of dietary fat and di-2ethylhexyl phthalate on tissue lipids in rats. Journal of Nutrition 1974 104 187-191. (https://doi.org/10.1016/0300-483x(74)90042-0)

41 Johansson M, Johansson N \& Lund BO. Xenobiotics and the glucocorticoid receptor: additive antagonistic effects on tyrosine aminotransferase activity in rat hepatoma cells. Basic and Clinical Pharmacology and Toxicology 200596 309-315. (https://doi. org/10.1111/j.1742-7843.2005.pto960406.x)

42 Zhang J, Zhang J, Liu R, Gan J, Liu J \& Liu W. Endocrine-disrupting effects of pesticides through interference with human glucocorticoid receptor. Environmental Science and Technology $201650435-443$. (https://doi.org/10.1021/acs.est.5b03731)

43 Chen Y, McCommis KS, Ferguson D, Hall AM, Harris CA \& Finck BN. Inhibition of the mitochondrial pyruvate carrier by tolylfluanid. Endocrinology 2017 [epub]. (https://doi.org/10.1210/en.2017-00695)

Received in final form 18 November 2017

Accepted 28 November 2017

Accepted Preprint published online 29 November 2017

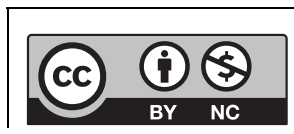

This work is licensed under a Creative Commons Attribution-NonCommercial 4.0 International License. 